\title{
Influence of Native Endophytes on Early Stages Growth of Vigna radiata (Moong) under Salt Stress Condition
}

Satavisha Mullick, Ramesh Kumar Kushwaha

10.18805/LR-4609

\begin{abstract}
Background: Green gram (Vigna radiata) also known as moong bean is an annually cultivated in East Asia, Southeast Asia and Indian subcontinent. $V$. radiata is very important source for the protein as in our regular diet and it proved essential amino acid such as phenylalanine, leucine, isoleucine, valine, lysine, arginine, methionine, threonine and tryptophan.

Methods: Here, we studied the influence of seed endophytes on germination and development under salinity stress condition. Seeds were treated with sodium hypochlorite for $30 \mathrm{~min}$ under shaking condition at $100 \mathrm{rpm}$ for surface sterilization and treated with $70 \%$ ethanol for $2 \mathrm{~min}$ and followed five times rinse with autoclaved water. Surface sterilised seeds were homogenised in autoclaved water with the help of mortal-pestle. Homogenised seed solution made serial dilution and spreaded over nutrient agar for endophytic bacterial growth. Seeds were treated with bacteriocide and fungicide to make endophytes free, followed by sown for germination at $0 \mathrm{mM}, 50 \mathrm{mM}, 100 \mathrm{mM}$ and $150 \mathrm{mM} \mathrm{NaCl}$ concentration.

Result: Endophyte free seedlings were more susceptible against salt stress over normal seedlings. Therefore endophyte free seedling shoot and root biomass was $23.5 \%$ and $65.7 \%$ lower than control seedling biomass at $0 \mathrm{mM}$ salt respectively, while root length was $70 \%$ lower than control seedling root at $0 \mathrm{mM}$ salt concentration. Proline content in shoot and root observed an increase with increase of salt concentration. At $0 \mathrm{mM}$ salt, proline content was $0.00782 \pm 0.00043$ and $0.00648 \pm 0.00017(\mu \mathrm{mol} / \mathrm{mg})$ in root of normal and endophyte free seedling respectively, while in shoot, it was non-significant difference. Glycine betaine content found to be increasing upto $100 \mathrm{mM}$, followed by decreasing at $150 \mathrm{mM}$ in both root and shoot tissue. Glycine betaine content in endophyte free and control seedling shoot was $74.2 \pm 2.5$ and $96.0 \pm 2.73(\mu \mathrm{g} / 200 \mathrm{mg})$ respectively at $100 \mathrm{mM}$ salt concentration. This result suggests, not only heritable genomic DNA but also endophytes associated with seed are very much important for the seedling growth and development which is also finally helps to combat abiotic stress situation.
\end{abstract}

Key words: Bacteriocide, Endophyte, Fungicide, Glycine betaine, Proline, Vigna radiata.

\section{INTRODUCTION}

Vigna radiata also called Green gram or moong bean or mash, which is annually cultivated in East Asia, Southeast Asia and Indian subcontinent. It belongs to the legume family and seed is rich source of protein, vitamin B complex, calcium and potassium (Oghbaei and Prakash, 2017). Root associated with rhizobium for the nitrogen fixation, phosphate solublisation, siderophore formation, phytohormone production and help in biotic and abiotic stress in leguminous plants. (Gopalakrishnan et al. 2015). Apart from rhizobium, others endophytic fungi and bacteria are associated with Vigna radiata have been isolated from non- rhizobial root tissue (Pandya et al. 2015). Non-rhizobial endophytes were also bearing similar character as of rhizobium like, phytohormone secretion, nutrient solubilisation, antipathogenic activity etc, to induce the plant growth of $V$. radiata (Bhutani et al. 2018). Endophytic microbes (fungi or bacteria) are very important for medicinal and non-medicinal plant, have been reported from most of plant species. The role of endophytes are not limited to help in growth of host, but also known to induce the secondary metabolites within host (Kushwaha et al. 2019). Plant carry their heritable character in genomic DNA from one generation next generation but the influence of seed associated endophytes on seedling growth cannot be avoided (Shahzad et al. 2018).
School of Biochemistry, REVA University, Rukmini Knowledge Park, Kattigenahalli, Yelahanka, Bangalore-560 064, Karnataka, India.

Corresponding Author: Ramesh Kumar Kushwaha, School of Biochemistry, REVA University, Rukmini Knowledge Park, Kattigenahalli, Yelahanka, Bangalore-560 064, Karnataka, India. Email: kushwaha.rameshkumar@gmail.com

How to cite this article: Mullick, S. and Kushwaha, R.K. (2021). Influence of Native Endophytes on Early Stages Growth of Vigna radiata (Moong) under Salt Stress Condition. Legume Research. DOI: $10.18805 /$ LR-4609.

Submitted: 15-03-2021 Accepted: 24-06-2021 Online: 31-07-2021

Salinity is one of the major threats in crop to decrease in the shoot length, root length and weight of the plants which enormously impacted leading to decrease in crop production (Machado and Serralheiro, 2017). High salt concentration influenced on biochemicaland physiological trait of plant such as ion homeostasis, uptake, osmolyte synthesis, antioxidant enzyme activation, synthesis of antioxidant compounds and polyamines, nitric oxide and hormone modulation (Sharma et al. 2019). The main protective osmolytes are proline, glycine betaine, polyols and sugar, while their accumulation in varying amounts amongst different plant species (Gupta and Huang 2014). Water soluble proline rise intracellular concentration in response to 
salinity stress and also serves as reserve of nitrogen source during stress recovery (Hayat et al. 2012). The importance of proline and glycine betaine in Nicotiana tabacum has been reported to increase the activity of antioxidant enzymes to decrease the reactive oxygen species for defence response (Hoque et al. 2008). Glycine betaine is an amphoteric quaternary ammonium compound, highly soluble in water and raises their concentration during salt stress condition. Glycine betaine act as osmotic protectant, protect enzymes/proteins, reduce reactive oxygen and protects the photosynthetic system during osmotic or salt stress (Giri, 2011). Both proline and glycine betaine are important osmolyte to protect Oryza sativa seedling during salt stress (Hasanuzzaman et al. 2014).

The influence of seed endophytes on seed germination under saline condition has not yet been explored in Vigna radiata. In concern with innate endophytes associated with moong seed and their influence on seedling development and growth under salt condition studied in vitro condition.

\section{MATERIALS AND METHODS}

\section{Fungicide and bacteriocide treatment to seed}

Local variety moong - Pusa Baisakhi seeds were purchased from Kattigenahalli market, Bangalore, India. 10 gram seeds were inoculated in autoclaved $100 \mathrm{ml}$ conical flask containing $20 \mathrm{ml}$ distilled water and supplemented with antibiotics streptomycin $(0.2 \mathrm{mg} / \mathrm{ml})$, tetracycline $(0.2 \mathrm{mg} / \mathrm{ml})$ and fungicide mancozeb 75 WP $(1 \mathrm{mg} / \mathrm{ml})$ for overnight at room temperature under shaking condition. Mancozeb was purchased in January, 2019 which was prohibited to be manufactured and sold from May, 2019 by the Ministry of Agriculture and Farmers Welfare in India. The study was carried out in REVA University, Bangalore from the month of February 2019 to April 2021. Initially, different concentration of the antibiotics streptomycin $(2 \mathrm{mg} / \mathrm{ml}$, $1 \mathrm{mg} / \mathrm{ml}, 0.5 \mathrm{mg} / \mathrm{ml}, 0.1 \mathrm{mg} / \mathrm{ml}, 0.01 \mathrm{mg} / \mathrm{ml}$ ) and tetracycline $(2 \mathrm{mg} / \mathrm{ml}, 1 \mathrm{mg} / \mathrm{ml}, 0.5 \mathrm{mg} / \mathrm{ml}, 0.1 \mathrm{mg} / \mathrm{ml}, 0.01 \mathrm{mg} / \mathrm{ml})$ were used, while fungicide $(1 \mathrm{mg} / \mathrm{ml})$ remained constant during all time.

\section{Isolation of seed associated bacterial endophytes}

Seeds were treated with $20 \%$ sodium hypochlorite for 30 min under shaking condition at $100 \mathrm{rpm}$ for surface sterilization and then washed with distilled water under aseptic condition (Kushwaha et al. 2019). Thereafter, seeds were treated with $70 \%$ ethanol for $2 \mathrm{~min}$ and followed five times rinse with autoclaved water. To check the surface sterilization, last wash water was spread on nutrient agar (NA) and potato dextrose agar (PDA) for bacterial and fungal growth respectively. Surface sterilized seeds were macerated in distilled water with help of autoclaved mortar and pestle under aseptic condition. $10^{-1}$ to $10^{-9}$ serial dilution made from macerated seed solution and $100 \mu$ from each dilution were spread on nutrient agar to isolate the seed associated endophytic fungi.

\section{Evaluation of endophyte free seedlings}

Fungicide and bacteriocide treated seeds were five times washed with distilled water, followed by macerated in distilled water with help of sterilized mortar and pestle under laminar. $100 \mu \mathrm{l}$ of macerated seed solution were spread on nutrient agar and potato dextrose agar media to check bacterial growth and the fungal growth respectively. For bacterial growth, NA plates were kept at $37^{\circ} \mathrm{C}$ for overnight and to check fungal growth PDA plates were kept at $30^{\circ} \mathrm{C}$ for a week.

\section{Seed germination under salt stress}

Bacteriocide and fungicide treated or untreated control seeds were kept on sterilized blotting sheet in petriplate. 1012 seeds were placed in each plate in three replication. $10 \mathrm{ml}$ of salt solution added and was kept at ambient condition for seedling development. Different salt concentrations of sodium chloride $(0 \mathrm{mM}, 50 \mathrm{mM}, 100 \mathrm{mM}$, $150 \mathrm{mM}$ ) were prepared in distilled water. Seeding growth was observed every day upto 10 days. After 10 days, samples were collected for the fresh biomass, height, proline and glycine betaine estimation in all treatments.

\section{Proline estimation}

Proline was estimated according to (Bates et al. 1973), approximately $500 \mathrm{mg}$ of plant material (root andshoot) was homogenized into $10 \mathrm{ml}$ of $3 \%$ sulphosalicylic acid and filtered with Whatman filter paper \#2. $2 \mathrm{ml}$ of filtrate was mixed with $2 \mathrm{ml}$ of acidic ninhydrin and $2 \mathrm{ml}$ glacial acetic acid in the test tube. Thereafter, reaction mixture was kept at $100^{\circ} \mathrm{C}$ in water bath for 1 hour and then reaction terminated in ice. In this reaction mixture $4 \mathrm{ml}$ toluene was added and was mixed vigorously for 15-20 seconds. Upper layer of toluene containing chromophore used to take the absorbance at $520 \mathrm{~nm}$ and toluene taken as blank.

\section{Glycine betaine estimation}

Glycine betaine was estimated according to Grieve and Grattan, 1983, approximately $500 \mathrm{mg}$ of shoot or root tissues was grinded in $5 \mathrm{ml}$ distilled water and kept in shaking condition at $25^{\circ} \mathrm{C}$ for 24 hours. The extract was mixed with sulphuric acid and potassium tri-iodide and then kept on ice for 90 mins. The reaction was terminated by adding chilled 1,2-dichloro ethane and kept for phase separation at room temperature for 2 hours. After phase separation, lower organic layer was taken for absorbance at $365 \mathrm{~nm}$. Glycine betaine content in root and shoot tissue was estimated with the help of standard glycine betaine.

\section{Statistical analysis}

For each salt treatment, three biological and three technical replicates were considered for statistical analysis. The statistical significant differences between two samples were tested by unpaired Student's t-test though online software (http://www.socscistatistics.com/tests/studentttest/ 
Default2.aspx). Each treatment was followed with six biological replicates. Asterisks indicate a significant difference from the control (Student's t-test; ${ }^{* *} \mathrm{P}<0.05$, $\left.{ }^{\star * *} \mathrm{P}<0.01\right)$. Cont, Control; EF, Endophyte free.

\section{RESULTS AND DISCUSSION}

Influence of endophyte on plant biomass under salt stress

Endophytes are recognized as hidden world within plant and their importance for the host benefit are reported by numerous researchers. Endophytes help to plant through secretion of phytohormone hormone, phosphate solublization, nitrogen fixation, sidrophore production and also help during abiotic and biotic stresses (Khandel et al. 2017). The morphology of normal seedling observed better than the endophyte free seedling at each salt concentration (Fig 1). At 0mM control, the control seedling biomass and endophyte free seedling biomass was $331 \pm 7.11$ and $253.6 \pm 8.02 \mathrm{mg} /$ plant respectively (Fig 2). Plant biomass was decreasing with increasing salt concentration in both normal and endophyte free seedling. At $50 \mathrm{mM}$, control and endophyte free seedling biomass was decreased by $11.6 \%$ and $14.3 \%$ respectively (Fig 2a,b). At $100 \mathrm{mM}$, control seedling biomass was decreased by $23.2 \%$ while in case of endophyte free seedling decreased by $17.2 \%$ than their respective control (Fig 2a,b). However, at $100 \mathrm{mM}$ control seedling and endophyte free seedling biomass was decreased by $28 \%$ and $31.2 \%$ respectively to their respective control (Fig 2a,b). In both seedling, salt treatment was influencing in similar fashion but normal seedling was having more biomass at each salt concentration than endophyte free seedling (Fig 2a,b). Previously, 22 endophytic bacteria were isolated from Vigna radiata roots and some of bacteria were retaining plant growth promoting activity (Bhutani et al. 2018). Among abiotic stress, salt stress is very common; alleviating salt concentration in soil day by day as well as saline affecting area increasing worldwide is a big problem (Shrivastava and Kumar, 2015). Therefore, the colonization endophyte Serendipita indica (formerly Piriformospora indica) with Arabidopsis helps to grow under salinity stress (Lanza et al. 2019).

Recently, 25 endophytic microbes were reported from the root of Vigna radiata and some of them showed growth promoting characteristic (Gujar et al. 2019). When other sources are compared for the endophytes, the seed is one heritable source which carried from one generation to the next (Shahzad et al. 2018). Previous study showed that through direct and indirect mechanism endophytes help in

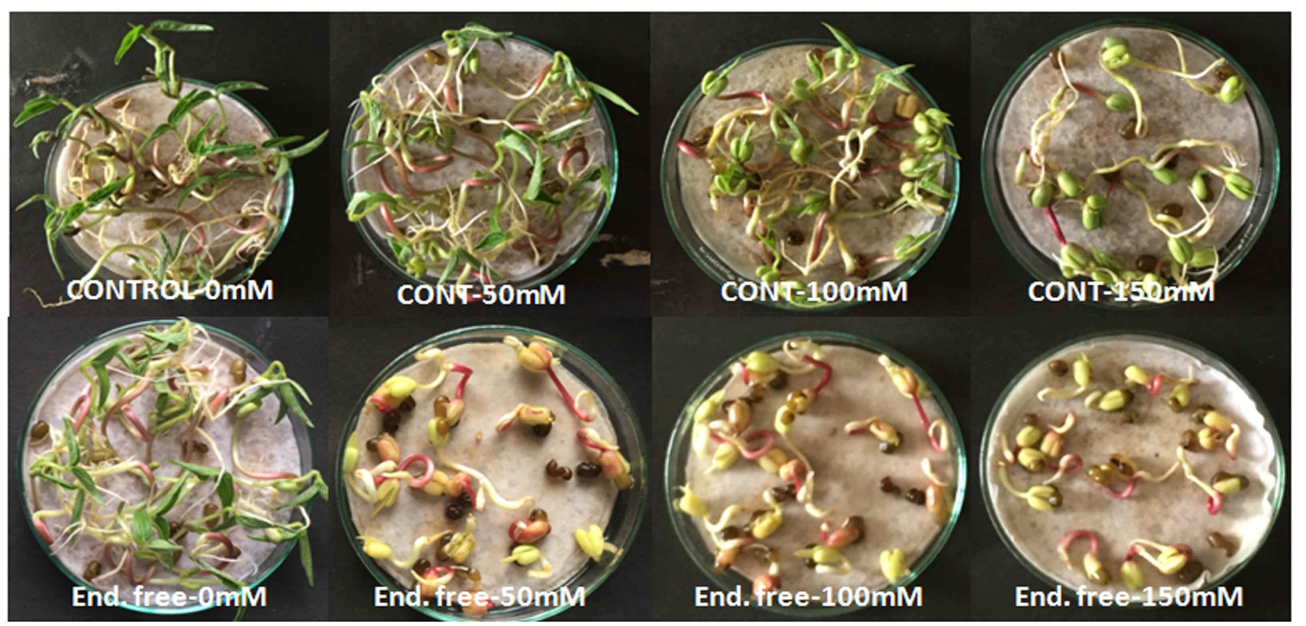

Fig 1: Image of control and endophyte free seedling growth under different salt stress condition after 5 days of incubation. CONTControl, End. free- Endophyte free.

(a)

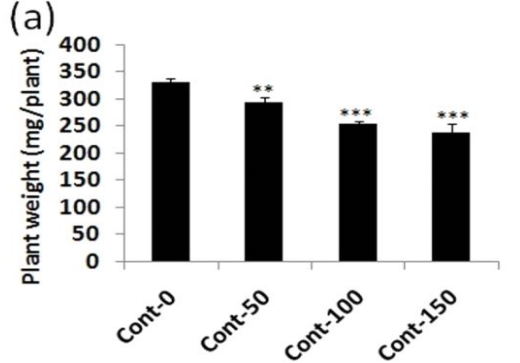

(b) 300

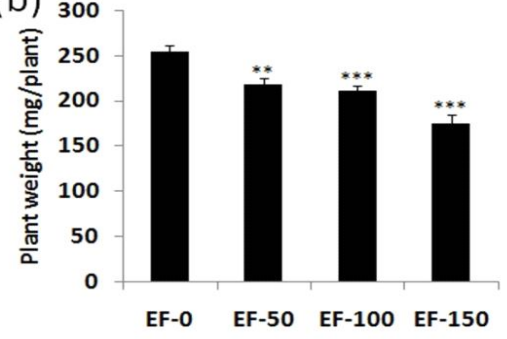

Fig 2: Effect of salt on fresh biomass (a) control seedling plant biomass at different salt concentration (b) endophyte free seedling biomass at different salt concentration. 
germination and promotion of plant growth (Walitang et al. 2019). In present study, biomass was decreasing with increasing salt concentration, but biomass decreasing rate observed higher in endophyte free seedling as compared to control. Of course, in control seedling endophyte was present and might be helping plant to resist in salt condition. Rather than the plant surfaces the internal tissues of plant provide a protective environment for the endophytes where temperature, osmotic pressure and UV radiation does not affect the surviving of the bacteria in such extreme environmental conditions (Thamiz Vendan and Balachandar, 2021). Seed endophyte bacterial community also depends on the genotype of plant and salt stress trigger the dominant of important class of bacteria to help under stress condition (Walitang et al. 2018).

\section{Influence of endophyte on shoot and root length under salt stress}

Salt stress is negatively influenced on morphology, physiology, plant biomass and yield (Gupta et al. 2014). But the application of endophytic bacteria has been recognized for adaptation under salt stress condition (Vaishnav et al. 2019). Shoot and root length of control seedling was higher than endophyte free seedling at each salt treatment (Fig 3). Shoot length of control seedling and endophyte free was $5.5 \pm 0.5$ and $1.6 \pm 0.15$ (cm/plant) at $0 \mathrm{mM}$ salt concentration (Fig 3a,b). As the salt concentration was increasing, the shoot length was decreasing by $45.4,78.8$ and $89.6 \%$ at 50,100 and $150 \mathrm{mM}$ respectively in control seedling
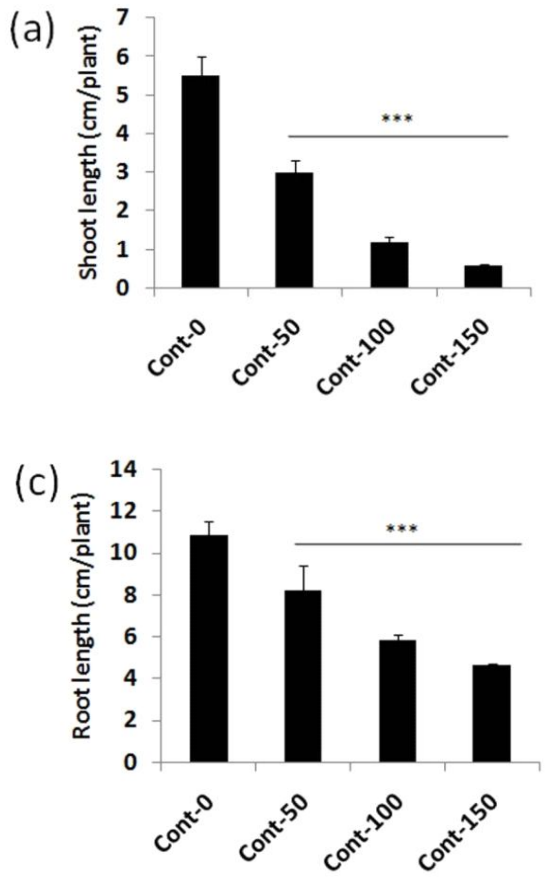

(Fig 3a). In case of endophyte free seedling, shoot length was decreasing by $14.1,42.7$ and $71.3 \%$ at 50,100 and $150 \mathrm{mM}$ salt concentration respectively (Fig $3 \mathrm{~b}$ ). With increasing the salt concentration, shoot length decreasing rate was higher in control seedling plant than endophyte free seedling (Fig 3a,b).

Root length was higher in control seedling as compared with endophyte free at every salt concentration. At $0 \mathrm{mM}$, root length of control seedling and endophyte free seedling were $10.8 \pm 0.72$ and $3.73 \pm 0.25 \mathrm{~cm} /$ plant respectively, i.e. endophyte free seedling length was $65.7 \%$ less than control seedling (Fig 3b,c). In control seedling, root length was 24 , 45.9 and $57.4 \%$ decreased at 50, 100 and $150 \mathrm{mM}$ respectively comparedwith their $0 \mathrm{mM}$ control (Fig 3c). However, root length of endophyte free seedling was decreased by $22.2,33.8,80.3 \%$ at 50,100 and $150 \mathrm{mM}$ respectively than their control plant (Fig 3d). At $100 \mathrm{mM}$, endophyte free seedling was not able to grow properly and their root length was very less than control seedling root length. In present finding, the control seedling was retaining higher root length, shoot length and plant biomass as compared with endophyte free seedling at $0 \mathrm{mM}$ and higher salt. Previously reported that, the application of bacterial endophyte Gordonia terrae KMP456-M40 has been enhanced the root length of mangrove seedlings and the biomass of salt-stressed rice under axenic conditions up to $65 \%$ and $62 \%$, respectively (Soldan et al. 2019). The highest seedling length, dry weight and germination percentage was observed in the green grams inoculated with isolate KHDEB5
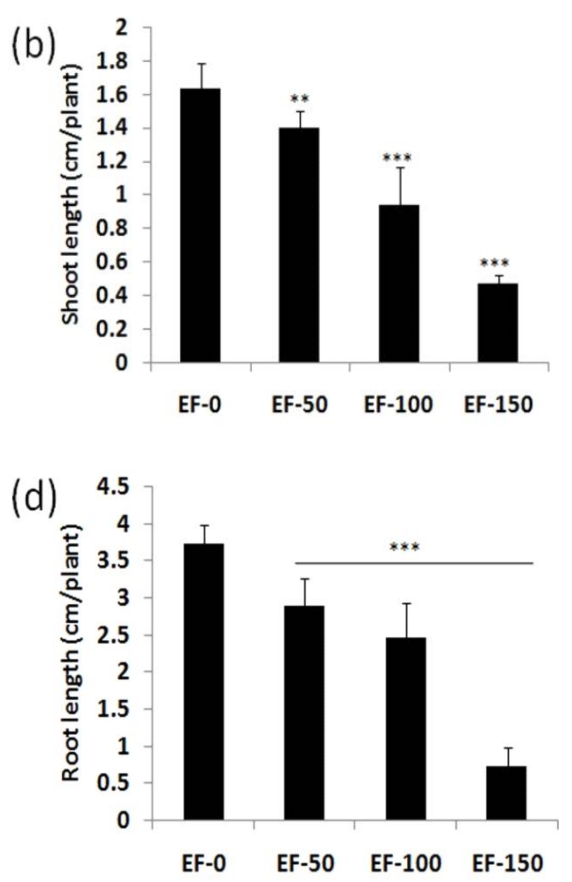

Fig 3: Effect of salt on root and shoot length (a) shoot length of control seedling at different salt concentration (b) shoot length of endophyte free seedling at different salt concentration (c) root length of control seedling at different salt concentration (d) root length of endophyte free seedling at different salt concentration 
under salt stress varying upto a wide range of salt concentration (upto 500mM NaCl) (Das et al. 2020). From same leguminaceae family plant, four endophytes, Bacillus cereus NUU1, Achromobacter xylosoxidans NUU2, Bacillus thuringiensis NUU3 and Bacillus subtilis NUU4 were isolated from Cicer arietinum root, however only B. subtilis NUU4 significantly improved plant growth, symbiotic relation with rhizobia and yield under saline soil condition (Egamberdieva et al. 2017).

\section{Proline content in control and endophyte free seedling} under salt stress

Proline is very important osmolyte to protect plant under abiotic stress condition and increasing content with increasing salt concentration upto certain extent (Kaur and Asthir, 2015). At 0mM salt concentration, the proline content in shoot was not significant difference between control and endophyte free seedlings (Fig 4a,b). Proline content in control seedling shoot at 50 and $100 \mathrm{mM}$ was increased by $69.2 \%$ and $115.4 \%$ respectively compared with $0 \mathrm{mM}$ salt treatment (Fig 4a). Proline content was not increasing with increasing salt, because at $150 \mathrm{mM}$ proline content in control seedling was increased by $54.7 \%$ as compared with $0 \mathrm{mM}$ salt (Fig 4a). In endophyte free seedling shoot, proline content was maximum at $50 \mathrm{mM}$ salt then followed by decreasing with increasing salt (Fig 4b). At 50, 100 and $150 \mathrm{mM}$ salt concentration, proline content was increased by $85.9,35.1$ and $29.6 \%$ as compared with $0 \mathrm{mM}$ salt of endophyte free seedling shoot (Fig 4b).
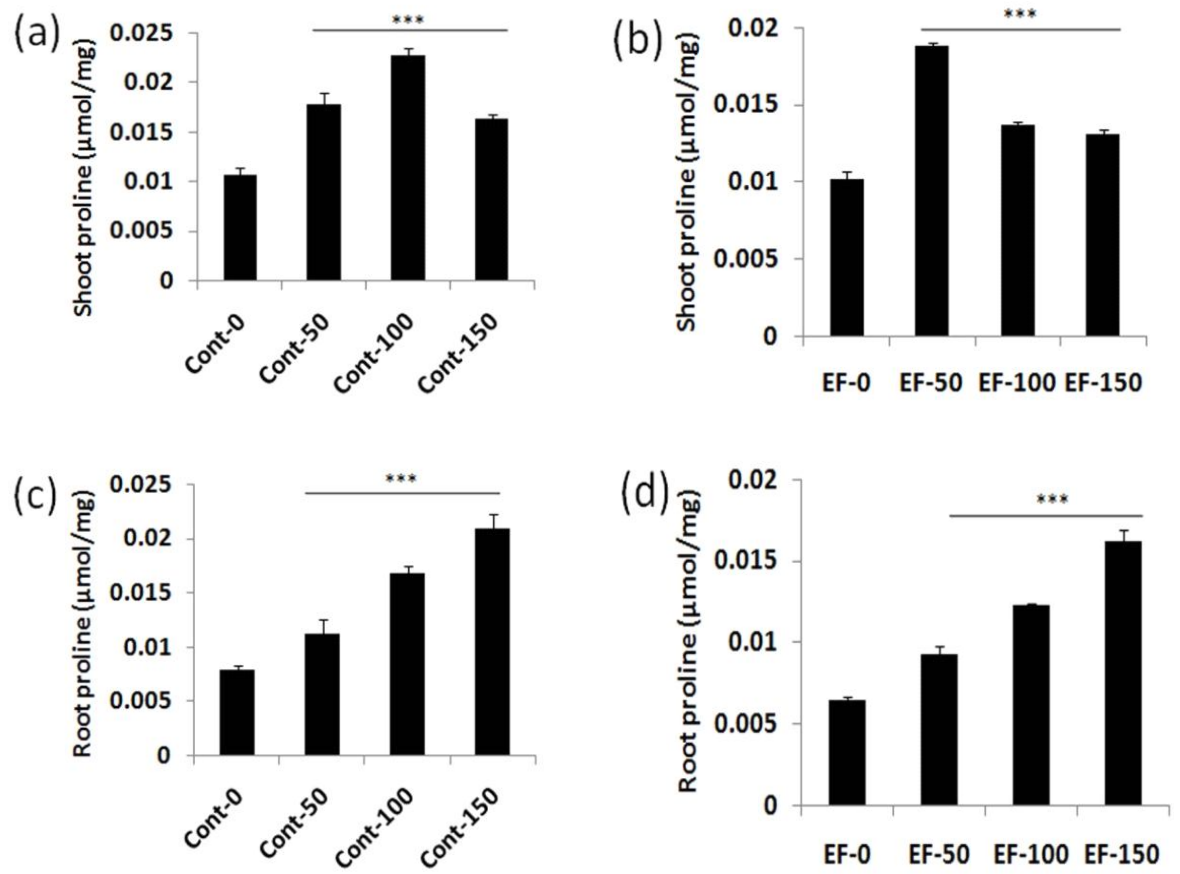

Fig 4: Effect of salt on proline content in root and shoot tissue (a) proline content in shoot of control seedling at different salt concentration (b) proline content in shoot of endophyte free seedling at different salt concentration (c) proline content in root of control seedling at different salt concentration (d) proline content in root of endophyte free seedling at different salt concentration. 

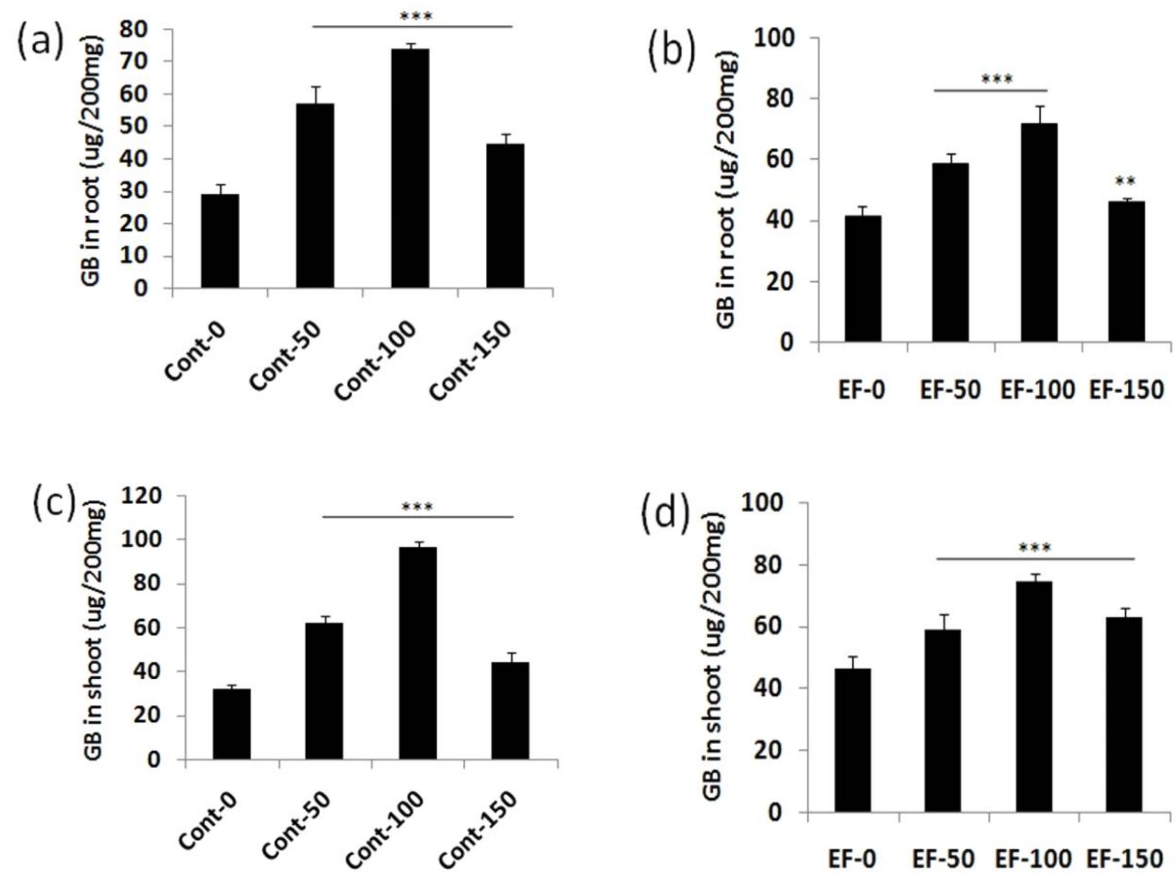

Fig 5: Effect of salt on glycine betaine (GB) content in root and shoot tissue (a) GB content in root of control seedling at different salt concentration (b) GB content in root of endophyte free seedling at different salt concentration (c) GB content in shoot of control seedling at different salt concentration (d) GB content in shoot of endophyte free seedling at different salt concentration.

\section{Glycine betaine content in control and endophyte free seedling under salt stress}

Glycine betaine (GB) is an amphoteric quaternary ammonium compound and is ubiquitously reported in microorganism, animal and from plant. GB is non-toxic, soluble in water and remainselectrical neutral at wide range of $\mathrm{pH}$ (Gupta et al. 2014). GB content in root and shoot tissue was increased upto $100 \mathrm{mM}$, afterward decreased at $150 \mathrm{mM}$ salt concentration (Fig 5). Either in shoot or root, the GB content was higher in control seedling than endophyte free seedling plant (Fig 5). In control seedling, the GB was 91.5 and $198.4 \%$ higher in shoot at 50 and $100 \mathrm{mM}$ as compared with $0 \mathrm{mM}$ salt (Fig 5a). But at $150 \mathrm{mM} \mathrm{GB}$ in shoot decreased and it was only $37.6 \%$ higher than $0 \mathrm{mM}$ salt concentration (Fig 5a). GB content in endophyte free seedling shoot was also following same pattern. At 50 and $100 \mathrm{mM}$, GB content was 27.5 and $61 \%$ higher in endophyte free seedling shoot respectively as compared with $0 \mathrm{mM}$ salt, while at $150 \mathrm{mM}$ GB content was $36.9 \%$ higher than $0 \mathrm{mM}$ salt concentration (Fig 5b).

In abiotic stress condition, spatio-temporal accumulation of GB provides osmotic adjustment, stabilizes proteins and protects the photosynthetic apparatus (Annunziata et al. 2019). Salt stress damage to photosynthetic pigment and apparatus, accumulation of GB during salt stress and foliar spray of GB led to pigment stabilization and increase in photosynthetic rate and growth of plant (Cha-Um and Kirdmanee, 2010). Transgenic wheat (betaine aldehyde dehydrogenase, $B A D H$ ) was accumulated upto $42 \mathrm{mmol} \mathrm{L}^{-1}$, showed higher net photosynthetic rate and stomatal conductance over control at $200 \mathrm{mM}$ salt concentration (Umar et al. 2018, Tian et al. 2016).

In root, GB content was induced maximum at $100 \mathrm{mM}$ salt concentration in both control and endophyte free seedling. In control seedling root, GB content was 95.3 and $153.2 \%$ higher at 50 and $100 \mathrm{mM}$ salt concentration respectively than $0 \mathrm{mM}$ salt, while at $150 \mathrm{mM}$ it was $52.1 \%$ higher than $0 \mathrm{mM}$ salt (Fig $5 \mathrm{c}$ ). In case of endophyte free seedlings, GB content was 41.3 and $72.2 \%$ higher at 50 and $100 \mathrm{mM}$ salt concentration respectively than $0 \mathrm{mM}$ salt, however at $150 \mathrm{mM}$, it was only $10.6 \%$ higher than $0 \mathrm{mM}$ salt (Fig 5d). In present study, GB content in root and shoot was increasing with increasing salt upto $100 \mathrm{mM}$. But GB was higher in shoot as compared with root at each salt concentration as support the previous finding spatiotemporal accumulation of GB (Annunziata et al. 2019). Abide to $G B$ and proline, the external spay of polyamines (putrescine, spermidine and spermine) help to salt tolerance by enhanced the contents of glutathione and ascorbate, increased activities of antioxidant enzymes (dehydroas corbatereductase, glutathione reductase, catalase and glutathione peroxidase) and glyoxalase enzyme (glyoxalase II) in moong seedling (Nahar et al. 2016).

\section{CONCLUSION}

In present finding elucidated the importance of endophytes associated with seed. Endophyte seedling were retaining less proline and GB content in root and shoot as compared 
with control seedling i.e without bacteriocide or fungicide treated seedling. Total eight endophytic bacteria were present interior of seed which opened a new window to find out the potential endophytic bacteria which will be responsible for seedling germination and growth under ionic stress situation.

\section{ACKNOWLEDEGEMENT}

The authors are grateful for encouragement and support of Chancellor, REVA University, India. Authors express sincere thanks to the HOD, School of Biochemistry, REVA University, India for her support and encouragement. Authors declare that they have no conflict of interest.

\section{REFERENCES}

Annunziata, M.G., Ciarmiello, L.F., Woodrow, P., Dell'Aversana E. and Carillo, P. (2019). Spatial and temporal profile of glycine betaine accumulation in plants under abiotic stresses. Frontiers in Plant Science. 10: 230. https:// doi.org/10.3389/fpls.2019.00230.

Bates, L.S., Waldren, R.P. and Teari, D. (1973). Rapid determination of free proline for water stress studies. Plant and Soil. 39: 205-207. https://doi.org/10.1007/BF00018060.

Bhutani, N., Maheshwari, R. and Suneja, P. (2018). Isolation and characterization of plant growth promoting endophytic bacteria isolated from Vigna radiata. Indian Journal of Agricultural Research. 52: 596-603. DOI: 10.18805/ IJARe.A-5047.

Cha-Um, S. and Kirdmanee, C. (2010). Effect of glycinebetaine on proline, water use and photosynthetic efficiencies and growth of rice seedlings under salt stress. Turkish Journal of Agriculture and Forestry. 34: 517-527. DOI:10.3906/ tar-0906-34.

Das, R., Pradhan, M., Sahoo. R.K., Mohanty. S., Kumar, M. (2020). Isolation, identification and role of novel endosymbiotic bacterium Rhizobium pusence in root nodule of green gram cv. OUM-11-15 (Vigna radiata L.) under salinity Stress. Legume Research. 43. DOI:10.18805/LR-4239.

Egamberdieva, D., Wirth, S.J., Shurigin, V.V., Hashem, A. and Abd Allah, E.F. (2017). Endophytic Bacteria Improve Plant Growth, Symbiotic Performance of Chickpea (Cicer arietinum L.) and Induce Suppression of Root Rot Caused by Fusarium solani under Salt Stress. Frontiers in Microbiology, 8: 1887. DOI: $10.3389 /$ fmicb.2017.01887.

Giri, J. (2011). Glycine betaine and abiotic stress tolerance in plants. Plant Signaling and Behavior. 6: 1746-1751. doi: 10.4161/psb.6.11.17801.

Gopalakrishnan, S., Sathya, A., Vijayabharathi, R., Varshney, R.K., Gowda, C.L. and Krishnamurthy, L. (2015). Plant growth promoting rhizobia: challenges and opportunities. 3 Biotech. 5: 355-377. doi: 10.1007/s13205-014-0241-x.

Gujar, N., Murab, T. and Chandurkar, P. (2019). Evaluation of the Plant Growth Promoting Potential of Endophytic Bacteria Isolated from Vigna radiata $(\mathrm{L})$. International Journal of Research in Advent Technology. 7: 5. DOI: 10.32622/ ijrat.752019101.

Gupta, B. and Huang, B. (2014). Mechanism of salinity tolerance in plants: physiological, biochemical and molecular characterization. International Journal of Genomics. 701596. https://doi.org/10.1155/2014/701596.

Hasanuzzaman, M., Alam, M.M., Rahman, A., Nahar, K. and Fujita, M. (2014). Exogenous proline and glycine betaine mediated upregulation of antioxidant defense and glyoxalase systems provides better protection against salt-induced oxidative stress in two rice (Oryza sativa L.) varieties. BioMed Research International, 757219. https:/ /doi.org/10.1155/2014/757219.

Hayat, S., Hayat, Q., Alyemeni, M.N., Wani, A.S., Pichtel, J. and Ahmad, A. (2012). Role of proline under changing environments: a review. Plant Signaling and Behavior, 7: 1456-1466. doi: 10.4161/psb.21949

Hoque, M.A., Banu, M.N.A., Nakamura, Y., Shimoishi, Y. and Murata, Y. (2008). Proline and glycinebetaine enhance antioxidant defense and methylglyoxal detoxification systems and reduce $\mathrm{NaCl}$-induced damage in cultured tobacco cells. Journal of Plant Physiology, 165(8), 813824. doi: 10.1016/j.jplph.2007.07.013.

Kaur, G. and Asthir, B. (2015). Proline: a key player in plant abiotic stress tolerance. Biologia Plantarum, 59. https://doi.org/ 10.1007/s10535-015-0549-3.

KaviKishor, P.B., Hima Kumari, P., Sunita, M.S. and Sreenivasulu, N. (2015). Role of proline in cell wall synthesis and plant development and its implications in plant ontogeny. Frontiers in Plant Science. 6: 544. doi: 10.3389/fpls. 2015.00544.

Khandel, S.L., Pierre, M.J. and Sharon, L.D. (2017). Bacterial Endophyte Colonization and Distribution within Plants. Microorganisms. 25(5): 77. https://doi.org/10.3390/micro organisms 5040077.

Kushwaha, R.K., Singh, S., Pandey, S.S., Kalra A. and Babu, C.S.V. (2019). Fungal endophytes attune with anolide biosynthesis in Withania somnifera, prime to enhanced withanolide A content in leaves and roots. World Journal of Microbiology and Biotechnology. 35: 20. https://doi.org/10.1007/ s11274-019-2593-1.

Lanza, M., Haro, R., Lorena, B.C. and Benito, B. (2019). The endophyte Serendipita indica reduces the sodium content of Arabidopsis plants exposed to salt stress: fungal ENA ATPases are expressed and regulated at high $\mathrm{pH}$ and during plant co cultivation in salinity. Environmental Microbiology. https://doi.org/10.1111/1462-2920.14619.

Machado, R.M.A. and Serralheiro, R.P. (2017). Soil Salinity: Effect on Vegetable Crop Growth. Management Practices to Prevent and Mitigate Soil Salinization. Horticulturae. 3: 30. https://doi.org/10.3390/horticulturae3020030.

Mattioli, R., Costantino, P. and Trovato, M. (2009). Proline accumulation in plants: not only stress. Plant Signaling and Behavior. 4: 1016-1018. https://oi.org/10.4161/psb.4.11.9797.

Nahar, K., Hasanuzzaman, M., Rahman, A., Alam, M.M., Mahmud, J.A., Suzuki, T. and Fujita, M. (2016). Polyamines Confer Salt Tolerance in Mung Bean (Vigna radiata L.) by Reducing Sodium Uptake, Improving Nutrient Homeostasis, Antioxidant Defense and Methylglyoxal Detoxification Systems. Frontiers in Plant Science. 7: 1104. doi: 10.3389/fpls.2016.01104

Oghbaei, M. and Prakash, J. (2017). Nutritional properties of green gram germinated in mineral fortified soak water: I. Effect 
of dehulling on total and bioaccessible nutrients and bioactive components. Journal of Food Science and Technology. 54: 871-879. doi: 10.1007/s13197-016-2382-x.

Pandya, M., Rajput, M. and Rajkumar, S. (2015). Exploring Plant Growth Promoting Potential of Non Rhizobial Root Nodules Endophytes of Vigna radiata. Microbiology, 84: 80-89. https://doi.org/10.1134/S0026261715010105.

Shahzad, R., Khan, A.L., Bilal, S., Asaf, S. and Lee, I.J. (2018). What Is There in Seeds? Vertically Transmitted Endophytic Resources for Sustainable Improvement in Plant Growth. Frontiers in Plant Science. 9: 24. https://doi.org/10.3389/ fpls.2018.00024.

Sharma, A., Shahzad, B., Kumar, V., Kohli, S.K., Sidhu, G.P.S., Bali, A.S., Handa, N., Kapoor, D., Bhardwaj, R. and Zheng, B. (2019).Phytohormones Regulate Accumulation of Osmolytes Under Abiotic Stress. Biomolecules. 9. doi: 10.3390/biom9070285.

Shrivastava, P. and Kumar, R. (2015). Soil salinity: A serious environmental issue and plant growth promoting bacteria as one of the tools for its alleviation. Saudi Journal of Biological Sciences, 22, 123-131. https://doi.org/10.1016/ j.sjbs.2014.12.001

Soldan, R., Mapelli, F., Crotti, E., Schnell, S., Daffonchio, D., Marasco, R., Fusi, M., Borin, S. and Cardinale, M. (2019). Bacterial endophytes of mangrove propagules elicit early establishment of the natural host and promote growth of cereal crops under salt stress. Microbiological Research. 223-225: 33-43. https://doi.org/10.1016/j.micres.2019.03.008.

Thamizh Vendan, R. and Balachandar, D. (2021). Assessing the plant growth-promoting traits and host specificity of endophytic bacteria of pulse crops. Legume Research. DOI:10.18805/LR-4491.

Tian, F., Wang, W., Liang, C., Wang, X., Wang, G. and Wang, W. (2016). Overaccumulation of glycine betaine makes the function of the thylakoid membrane better in wheat under salt stress. The Crop Journal. 5: 73-82. DOI: 10.1016/j.cj.2016.05.008.

Umar, J., Aliyu, A., Shehu, K. and Abubakar, L. (2018). Influence of Salt Stress on Proline and Glycine Betaine Accumulation in Tomato (Solanum lycopersicum L.). Journal of Horticulture and Plant Research. 1: 19-25. https://doi.org/ 10.18052/www.scipress.com/JHPR.1.19.

Vaishnav, A., Shukla, A.K., Sharma, A., Kumar, R. and Choudhary, D.K. (2019). Endophytic Bacteria in Plant Salt Stress Tolerance: Current and Future Prospects. Journal of Plant Growth Regulation. 38: 650-668. https://doi.org/10.1007/s00344018-9880-1.

Walitang, D.I., Kim, C.G., Kim, K., Kang, Y., Kim, Y.K. and Sa, T. (2018). The influence of host genotype and salt stress on the seed endophytic community of salt-sensitive and salt-tolerant rice cultivars. BMC Plant Biology. 18: 51. https://doi.org/10.1186/s12870-018-1261-1.

Walitang, D.I., Kim, K., Madhaiyan, M., Kim, Y.K., Kang, Y. and $\mathrm{Sa}, \mathrm{T}$. (2019). Characterizing endophytic competence and plant growth promotion of bacterial endophytes inhabiting the seed endosphere of Rice. BMC Microbiology. 17: 209. doi: 10.1186/s12866-017-1117-0. 